\title{
A Periferia da periferia: uma ciência-do-cotidiano desenvolvida pelos laboratórios regionais dos "mundos corporativos": um estudo de caso
}

\section{The periphery of peripheries: a daily-life-science developed byregional laboratories of "corporate worlds": a case study}

\section{Maria Cristina de Oliveira Cardoso}

Programa de Pós-Graduação em História das Ciências e das Técnicas e Epistemologia (HCTE), Universidade Federal do Rio de Janeiro (UFRJ). mcristinaocardoso@gmail.com orcid.org/0000-0001-8897-4974

\section{Regina Maria Macedo Costa Dantas}

Departamento de Música, Universidade Federal da Bahia (UFBA) regina@hcte.ufrj.br

orcid.org/0000-0001-9782-2008

Resumo. Este trabalho traz para a discussão uma "ciência-do-cotidiano", desenvolvida em empresas, que muitas vezes não é identificada como ciência. As adaptações em tecnologias "importadas" e a naturalização de um conhecimento localizado são alguns pontos que quase sempre desaparecem no relato final dos projetos. Sabedores que a história é contatada quase sempre pelo viés dos vencedores, esse trabalho se propõe a dar historicidade às imbricações, negociações e associações realizadas pelos atores que participaram do projeto de travessia de um cabo óticosubfluvial no rio Amazonas.

Palavras-chave:CTS. Interdisciplinar. Cientistas invisíveis. Mundos corporativos. História das ciências.

Abstract.This work brings to discussion a "daily-life-science" that was developed by companies and that usually are not identified as science.Adaptations of "imported" technologies and the naturalization of a more localized knowledge are some facts that almost always disappear in the final report of the projects. Knowing that the story is almost always told by the viewpoint of the winners, this work aims to give historicity to the interconnections, negotiations and 
associations made by the actors who participated in the crossing of a subfluvial optical cable in the Amazon River.

Keywords: STS. Interdisciplinary. Invisible scientist. Corporate worlds. History of science.

Recebido: 01/10/2017 Aceito: 27/10/2017 Publicado: 07/11/2017

\section{Introdução}

Falar de uma empresa de serviços no segmento de tecnologia do Brasil sem salientar os materiais e tecnologias importados, seriadeixar de lado a oportunidade de dar historicidade as "naturalizações" quase sempre necessárias desses artefatos. As empresas, esses "mundos corporativos", construídas e constituídas por profissionais de diversas disciplinas poderiam ser consideradas uma "rede de saberes" trabalhando com foco em um objetivo comum.

Os laboratórios,nesses mundos corporativos, são laboratórios vivos, alimentados diariamente por novos elementos capturados das narrativas da sociedade - umexercício contínuo de observação do mercado que precisa manter contexto e conteúdo imbricados. Dianteda necessidade de movimentos rápidos e adaptações de materiais e tecnologias,é possível identificar o desenvolvimento de uma ciência que aqui chamaremos de ciênciado-cotidiano.

Nem sempre a ciência-do-cotidiano é considerada ciência. As adaptações desenvolvidas nas empresas são muitas vezes descritas como gambiarras, invencionices, estudos não científicos.Figuerôa (1995, p.17) sugere que vemos aquilo que estamos doutrinados a ver: uma história de vencedores: "buscando o esperado, não encontramos o realizado (FIGUERÔA, 1995,p.17). Os diversos movimentos realizados são deixados de lado para configuramos as categorias analíticas da história dos vencedores. Nesse trabalho buscamos adotar um novo olhar para as atividades realizadas por profissionais dos mundos corporativos. Queremos encontrar o realizado, a ciência-do-cotidiano desses cientistas invisíveis e para isso trazemos a voz de um grupo de cientistasdo norte do Brasil. Tentaremos dar uma historicidade ao processo de construção de um projeto além de evidenciar as interações sociais que interferiram diretamente no produto final.

A ciência-do-cotidiano é quase sempre realizada localmente e, quando não é ignorada, se perde na burocracia ou na distância entre o local de ocorrência e a matriz da empresa - ou local de decisão. Depois que o produto está "funcionando", essas modificações e aprendizados se perdem na construção do relatório final. Latour descreve essa naturalização da seguinte forma: quando o produto se estabelece, as inscrições que deram forma ao mesmoperdem a importância (LATOUR, 2000,p.112). Adaptações, conhecimento tácito, contribuições da sociedade desaparecem no meio dos papéis e das 
hierarquias. Quase sempre apenas parte desse conhecimento poderá ser resgatada com a possibilidade desse conhecimento já ter sido transformado.

O projeto escolhido foi a travessia do rio Amazonas por cabo ótico subfluvial realizado por uma empresa de telecomunicações entre 2008 e 2017, do qual, eu Maria Cristina, coautora desse trabalho, participei. A etapa escolhida foi a chegada do cabo ótico subfluvial na ilha da Marchantaria, no rio Solimões, Estado do Amazonas. Engenheiros, administradores, biólogos, geógrafos, ambientalistas, profissionais de diversas áreas e a sociedade local participaram dessa etapa do projeto. Nosso relato se inicia no primeiro encontro entre uma equipe da empresa e os líderes comunitários da Ilha. Esse trabalho não tem a pretensão de demonstrar as técnicas de engenharia e de outras ciências utilizadas no projeto. A metodologia utilizada para o levantamento de dados foi de entrevistas, realizadas em julho de 2017, com a equipe responsável pela implantação do projeto. Essa equipe era oriunda do Estado do Amazonase nesse trabalho será nomeada como "Equipe Local". Vale ressaltar que todas as diretrizes, contratações de empresas de prestação dos serviços necessários para a implantação do projeto, bem como as demais equipes eram procedentes do sudeste do Brasil, mais precisamente do Rio de Janeiro.

\section{O projeto, a ciência-do-cotidiano e os cientistas invisíveis}

A primeira dificuldade encontrada foi chegar à ilha da Marchantaria. A equipe era composta de 15 pessoas e a opção escolhidapelos responsáveis pela contratação, situados no Rio de Janeiro, foi o aluguel de um barco de passeios. Foi necessário que os representantes da empresa, situados em Manaus, informassem que para chegar à ilha era necessário um conhecimento específico da geografia do lugar, do rio e das "ruas" formadas pelos igarapés ao redor da Ilha. O deslocamento de Manaus para a ilha da Marchantaria foi realizado, então, em pequenos barcos pilotados por moradores da ilha. Primeiro aprendizado: o rio também tem suas ruas e é necessário ter esse conhecimento para se deslocar.

Na reunião, com a liderança da comunidade e alguns moradores, foi possível verificar que o projeto tinha várias "partes" dissociadas. Apesar da apresentação em conjunto do projeto, na reunião cada um da equipe possuía um papel a desempenhar e um resultado a obter. $\mathrm{O}$ relato da Equipe Localsobre reunião onde o projeto foi apresentado à comunidade, por exemplo, só contempla a parte técnica.

As linhas gerais do projeto foram apresentadas para as comunidades da ilha em reunião em uma das escolas, com mapas com as rotas, amostras dos cabos que seriam utilizados, dos postes de fibra. (EQUIPE LOCAL, 2017)

$\mathrm{Na}$ entrevista realizada em 2017, logo, posterior a implantação, a Equipe Local não cita as outras partes do projeto que também foram expostas nessa reunião, como por exemplo, questões ambientais e contrapartidas para a comunidade. Desapareceram do projeto inicial as interações e desvios necessários realizadospara aaprovação do projeto pela comunidade local. Um exemplo desses desvios: a empresa trazia na bagagem o que ela entendia ser benefícios para a comunidade - banda larga, computadores, mas a 
comunidade solicitava energia cabeada, produto que não era de competência da empresa. O projeto precisou ser revisto para que fosse possível a utilização dos postes de fibra pela companhia de energia elétrica além da interação com a própria empresa de energia elétrica local.

Em outros momentos, ao longo do período de implantação, as equipes se depararam com situações em que o técnico e o sociocultural não se dissociavam. Segundo Cukierman (2007, p.212), é necessário um novo enquadramento, um novo "ângulo de aproximação do problema" para que o "técnico" e o "social/cultural" constituam um movimento de "co-modificação". Esse novo enquadramento trouxe para dentro do projeto, novos atores. Uma dessas situações, por exemplo, foi amudança ocorrida na metodologia de implantação do cabo no leito do rio Amazonas. Dois cabos de testes implantados com a mesma técnica dos cabos submarinos, técnica dominada pela empresa, romperam-se. A técnica utilizada (lançar o cabo no leito do rio) não se mostrou adequada, mas os engenheiros da empresa não conseguiam identificar a causa do rompimento. Foi necessária uma aproximação com a comunidade local para que se identificasse que uma das razões para os cabos terem rompido dava-se por uma atividade de pesca cuja técnica utilizada causava danos ao material.

Outros desvios e negociações foram realizados ao longo do projeto: empresas prestadoras de serviços internacionais foram trocadas por empresas locais $\mathrm{e}$ mergulhadores foram trocados por moradores experientes em mergulho no rio Amazonas, entre outros. Percebe-se nopróximo relato um conhecimento naturalizado e inserido no relato como conhecimento dos engenheiros:

\footnotetext{
Primeiro foi executado um projeto-piloto, no qual dois cabos de teste foram implantados desde uma das margens do Rio Solimões até a Ilha da Marchantaria. Eles acabaram rompendo-se, mas o aprendizado foi fundamental para o projeto definitivo, pois observamos ofensores que deveriam ser evitados e oportunidades a serem aproveitadas: os ribeirinhos usam uma técnica de pesca onde eles fazem boias com anzóis descerem a correnteza do rio e as recolhem alguns quilômetros abaixo. Isso fez com que anzóis engatassem nos dois cabos ópticos implantados para teste. Quando as boias eram recolhidas, o cabo óptico era puxado pelos pescadores, o que causava danos ao mesmo. (EQUIPE LOCAL, 2017)
}

Outrarazão para o rompimento dos cabos foi a identificação de valas no leito do rio resultantes do movimento das correntezas, que deixavam os cabos expostos, tais quais varais de roupas, aos galhos e vegetações arrastadas pelas correntezas. Após essas duas descobertas decorrentes de um conhecimento da sociedade local, optou-se por enterrar o cabo no leito do rio.

A indicação de que o cabo óptico deveria ser enterrado veio como resultado de um processo, que pode ser considerado um experimento. Primeiramente, cabos ópticos foram instalados conforme a orientação já existente na empresa; depois, foram observados os efeitos oriundos de um comportamento social (a pesca) e da natureza (correnteza) e, a partir destas observações é que surgiu a decisão final de enterrar o cabo. 
Após análise dos resultados desse teste piloto, foi elaborado um primeiro projeto onde o cabo óptico a ser usado possuiria uma armadura de aço similar à usada nos cabos submarinos e que, ao contrário desses, que são lançados sobre o leito do mar, o cabo subfluvial deveria ser enterrado no leito do rio. (EQUIPE LOCAL, 2017)

Destacamos,como um outro ponto importante, as modificações que a Equipe Local realizou em técnicas e tecnologias para adaptar o projeto à realidade local.

Como o cabo óptico seria enterrado no leito do rio, poderíamos implantá-lo na Ilha da Marchantaria diretamente enterrado no solo, mas seria uma tarefa muito difícil já que a ilha é cortada por vários igarapés. Optamos então por usar postes e cabo aéreo autossustentável [...]. As rotas ópticas aéreas na ilha procuraram então contornar os igarapés e usar os terrenos mais firmes para implantação dos postes, já que eram também as áreas com moradias dos residentes na ilha, que se ressentiam da ausência de energia elétrica. (EQUIPE LOCAL, 2017)

Percebe-se que a narrativa da Equipe Local já incorpora um conhecimento que, a priori, seria um conhecimento dos moradores (cheia, localização de igarapés). Tal conhecimento, na fala da Equipe Local, torna-se "naturalizado" e imbricado com o próprio projeto da empresa. Ao final, ler a narrativa da equipe somente, não se consegue perceber todo o esforço necessário para a "naturalização" do conhecimento.

Nas entrevistas realizadasem julho de 2017 foi possível verificar o orgulho da Equipe Local em participar do projeto no papel de morador da região.

[...] tenho o maior orgulho de ser um engenheiro do norte e de ter conseguido aplicar todo o conhecimento acadêmico que adquiri as peculiaridades da nossa região, vencendo desafios que grandes empresas, até mesmo as internacionais, não se sentiram capazes. (EQUIPE LOCAL, 2017)

Maria Tereza Lima, então diretora de operações da empresa, fez um relato em 2010, quando o projeto ainda estava em andamento. Esse relato traz uma visão dos vencedores: desapareceram o conhecimento dos moradores, as negociações e associações que foram realizadas no período.

Ao longo de 2009 foram realizados testes in loco [...], para avaliar a viabilidade dessa travessia. Os resultados obtidos após oito meses de experiência piloto mostraram que a experiência é viável. (LIMA, 2010, p.39)

As adaptações às tecnologias foram ocorrendo naturalmente, o conhecimento "universal", se misturando ao conhecimento da Equipe Local e ao conhecimento dos moradores.

Como era impossível deslocar para as margens máquinas de perfuração de dutos, em conjunto com uma empresa de Manaus instalamos uma perfuratriz em uma balsa e construímos os dutos por onde passaram os cabos, do rio para a margem, o que nunca tinha sido tentado, mas que se revelou um sucesso. (EQUIPE LOCAL, 2017)

Figuerôa (1995, p.22) aponta que quando se passa a duvidar da universalidade da ciência, começa-se a admitir que este conhecimento seja "socialmente negociado".

A partir do momento que se passa a duvidar de que a ciência seja um corpus universal (espacial e temporalmente) de conhecimento que reproduz e espelha, de maneira direta, a realidade e, ainda, que se passa a admitir que tal conhecimento seja socialmente negociado, o estudo do processo de inserção e 
desenvolvimento de disciplinas científicas em contextos diversos daqueles nos quais floresceram originalmente reveste-se de sentido e importância. (FIGUERÔA,1995, p.22)

A criatividade foi a saída para vários obstáculos encontrados pela Equipe Local. E uma destas saídas foi realizar um movimento de aproximação entre o técnico e o social. Segundo Latour (2000, p.232), "nunca estamos diante de 'ciência, tecnologia e sociedade', mas sim de uma gama de associações mais fortes e mais fracas[..]”.

\begin{abstract}
As empresas contratadas pela empresa foram orientadas a utilizar ao máximo possível de mão de obra local e a conduzir qualquer pleito dos moradores diretamente à Coordenação do Projeto. [...] Foram realizadas muitas modificações a partir de sugestões dos moradores. As rotas dos cabos na ilha praticamente foram definidas em conjunto com os moradores, em face da experiência que eles tinham em relação a identificação dos terrenos que alagavam nos períodos de cheia. (ENGENHARIA DO NORTE, 2017)
\end{abstract}

\title{
3. Conclusões
}

A partir da entrevista realizada com a Equipe Local foi possível identificar como a "história dos vencedores " pode ser contada de diferentes ângulos, desarticulando a referência hegemônica da ciência. Sair do eixo do mainstream da empresa, matrizregião sudeste-local de decisão e do discurso habitual nos possibilitou trazer para o centro da discussão o conhecimento local, a ciência-do-cotidiano, a modernidade estrangeira "naturalizada" pela periferia da periferia. Percebe-se na Equipe local o orgulho de participar do mainstream da empresa e da ciência, mas ao mesmo tempo de fazer parte de uma história local. Esse trabalho faz parte de uma pesquisa de mestrado em andamento. Acredita-se que a continuidade da pesquisa permitirá revelar experimentos e abordagens que contribuirão para apontarmos a atuação dos cientistas invisíveis em espaços não registrados pela historiografia das ciências.

\section{Referências}

CUKIERMAN, H.L.: Abrindo mão da polarização entre o técnico e o social/cultural, Pesquisas e Práticas Psicossociais 6, n.2, São João del-Rei, agosto/dezembro 2011. Disponível em:

$<$ https://www.ufsj.edu.br/portal2repositorio/File/revistalapip/volume6_n2/Cukierman.p df $>$, Acesso em : 17 ago 2017.

FIGUEIRÔA, S. F. M. As Ciências Geológicas no Brasil: Uma História Social e Institucional, 1875-1934, Hucitec, 1995.

LATOUR, B. Ciência em Ação: como seguir cientistas e engenheiros sociedade afora. São Paulo. Ed.Unesp, 2000.

, Cogitamus: Seis cartas sobre as humanidades científicas. São Paulo:

Editora 34, 2016. 
LIMA, M.T. A. : Banda Larga, expectativas para o Norte, Revista T\&C Amazônia, Ano VIII, Número 18, I Semestre de 2010, Fundação Centro de Análise, Pesquisa e Inovação Tecnológica (Fucapi), p.38, 2010. Disponível em:

$<$ http://tecamazonia.com.br/wp-content/uploads/2017/03/revista_tec_ed18.pdf $>$ Acesso em 30 set 2017. 